\title{
Seasonal Variation of Saponin Contents in Platycodon grandiflorum
}

\author{
Sook Young Lee ${ }^{1}$, Yi Zi Yan², Mariadhas Valan Arasuª \\ Naif Abdullah Al-Dhabi ${ }^{3}$ and Sang Un Park ${ }^{4^{*}}$ \\ ${ }^{1}$ Regional Innovation Center for Dental Science \& Engineering, Chosun University, \\ 309 Pilmun-daero, Dong-gu, Gwangju, 501-759, Korea. \\ ${ }^{2}$ Agricultural College of Yanbian University, Yanji 133002, Jilin, China. \\ ${ }^{3}$ Department of Botany and Microbiology, Addiriyah Chair for Environmental Studies, \\ College of Science, King Saud University, P. O. Box 2455, Riyadh 11451, Saudi Arabia. \\ ${ }^{4}$ Department of Crop Science, Chungnam National University, 99 Daehak-ro, Yuseong-gu, Daejeon, \\ 305-764, Korea.
}

http://dx.doi.org/10.13005/bbra/2013

(Received: 15 January 2016; accepted: 23 February 2016)

\begin{abstract}
The balloon flower (Platycodon grandiflorum A. DC) is well known as an ornamental plant and has been used as a vegetable and as a traditional medicinal plant over a long time period. The root parts of Platycodi Radix have rich quantities of saponin glycosides and other important phytochemical constituents. The present study aimed to investigate seasonal variation in saponin contents in P. Radix. Four important saponinsdeapio-platycoside E, platycoside E, platycodin D3, and platyconic acid-were analyzed from the roots of balloon flower collected at different growing times. The contents of all of the analyzed saponins varied significantly with the time of growing. A similar trend of accumulation occurred for deapio-platycoside $E$ and platycoside $E$. The highest concentrations of these two saponins were observed in August. The accumulation trends of platycodin D3 and platyconic acid in Platycodi Radix differed, in that the largest concentrations of these saponins were observed in May. Our results suggest that the time of harvest should take into consideration the accumulation of particular saponins, and that maximum accumulation of these compounds may occur in May or August.
\end{abstract}

Key words: Balloon Flower; Saponin; Seasonal Variation; Traditional Medicine.

The balloon flower (Platycodon grandiflorum) has a traditional historical importance in China for over 2,000 years. Recently, the historical importances were proved in modern medicine with the scientific evidences. Platycodi Radix, the root of balloon flower, is also used as a vegetable $^{1-3} \cdot$ P. grandiflorum is widely used as a traditional oriental medicine to treat coughs, colds, upper respiratory tract infections, sore throats, tonsillitis, and chest congestion ${ }^{4,5}$.

\footnotetext{
* To whom all correspondence should be addressed. Tel.: +82-42-821-5730; Fax: +82-42-822-2631; E-mail: supark@cnu.ac.kr
}

Platycodi Radix is known for the existence of high contents of saponins and triterpenoids. The indentified saponins are widely used for the treatment of inflammatory diseases, anti-allergic activities, cancer, immune modulatory responses and apoptosis ${ }^{6-9}$. Recently, it has been used for the treatment of diabetes, hypertension, hyperlipidemia, and obesity ${ }^{10,11}$. Saponins and triterpenoids are aboundant in the root part of plant whereas the other parts have comparatively less ${ }^{12}$. To date, more than 30 triterpenoid saponins have been isolated from this plant ${ }^{13}$.

Most of the research on balloon flower has been conducted to assess its medicinal value, and particularly to examine different types of saponins under varying growth conditions. To 
date, there have been no published reports on the seasonal variation of saponin content in this species. The objective of this study was to determine the optimum time of harvest to obtain maximum saponin content in Platycodi Radix.

\section{MATERIALSANDMETHODS}

\section{Plant Material}

Balloon flower (P. grandiflorum) seeds were germinated in a greenhouse, and the seedlings were cultivated in an experimental farm at the Agricultural College of Yanbian University (Longjing, China) on May 1, 2007 and allowed to grow until October 2008. After 10 months, roots of the balloon flower plants were harvested monthly (March 1 to October 1, 2008). The roots were collected and cleaned for the removal of the mud and other soil particles. After that the samples were packed in the sterile storage cover and kept in at $80^{\circ} \mathrm{C}$ until further analysis. The stored samples were frozen dried for at least $48 \mathrm{~h}$. Initially, the samples were kept at $-4^{\circ} \mathrm{C}$ for $3 \mathrm{~h}$, further at $-80^{\circ} \mathrm{C}$. After that that, the dried samples were ground for a fine powder. Quantification of the chemical components were done using HPLC.

\section{Total saponin extraction and HPLC analysis}

For extraction of saponins, $50 \mathrm{mg}$ of the powdered samples were mixed with $10 \mathrm{ml}$ of $100 \%$ $\mathrm{MeOH}$ for $30 \mathrm{~min}$ in a sonicator. After that, approximately, $4 \mathrm{ml}$ of the supernatant was concentrated, and the collected crude extract was re-suspended with $200 \mu \mathrm{l}$ of $\mathrm{MeOH}$. The collected extract was quantified using HPLC system (model NS-4000; Futecs Co., Daejeon, Korea). Four standard platycosides (deapio-platycoside E, platycoside E, platyconic acid, platycodin D3) were analyzed by HPLC with an evaporation light scattering detector (ELSD). The samples were separated on a Chemcopak column $(4.6 \times 150 \mathrm{~mm}$, $3 \mathrm{im}, 100$, Chemco, Japan) with a flow rate of $0.7 \mathrm{ml}$ $\mathrm{min}^{-1}$. Platycosides were separated by linear gradient between solution A ( $50 \mathrm{mM}$ ammonium acetate: acetonitrile: methanol, 75:20:5) and solution B (50 mM ammonium acetate: acetonitrile: methanol, 69:26:5). The gradient followed was: $100 \%$ A, $1-15$ $\min ; 48 \%$ B, 15-28 min; 50\% B, 28-33 min; 50\% B, 33-60 min; 60\% B, 60-73 min; 100\% B, 73-88 min. Saponins were identified and quantified by comparing the retention times and peak areas with standards or by direct addition of standards into the sample (spike tests). Sample aliquots were filtered through a 0.45-ìm polytetrafluoroethylene filter prior to injection. All samples were run in triplicate.

\section{RESULTS AND DISCUSSION}

The content of the 4 saponins (deapioplatycoside E, platycoside E, platyconic acid, platycodin D3) in Platycodi Radix varied significantly with growing time (Fig. 1), as described below.

\section{Deapio-platycoside E}

Deapio-platycoside E content varied significantly among growing seasons, and increased with increasing time of growing. The highest concentration of deapio-platycoside $\mathrm{E}$ was found in August, after which it started to decline; the content in March and April were much lower than that in the other months. Deapio-platycoside E content was approximately 6 times higher in August compared to its content in March or April.

\section{Platycoside E}

Platycoside E content in the root of balloon flower ranged from 1.28 to $3.34 \mathrm{mg} / \mathrm{g}$ DW at different growing times. The highest platycoside E content was observed in August; the August concentration was 2.6 times higher than that in October.. The content of platycoside $\mathrm{E}$ was lower during months with colder temperatures (March, April, and October) compared to months with warmer average temperatures.

\section{Platycodin D3}

Platycodin D3 content increased with increasing growing time and reached its highest level in May, after which it began to decline. Platycodin D3 content in May was 2.8 times higher than that in March, when the lowest concentration was observed. There was greater variability in Platycodin D3 content during early growth stages than after longer periods of growth.

\section{Platyconic acid}

Platyconic acid content was much higher than that of the other 3 saponins, and there was considerable variability in platyconic acid content among the different sampling times (from 1.39 to $6.48 \mathrm{mg} / \mathrm{g} \mathrm{DW}$ ). The highest content of this saponin 
was observed in May, when it was 4.5 times higher than in September when the lowest concentrations occurred.

Platycodin is the common term for the platycodon saponins. Several, structurally minor varied components were names as platycodin $\mathrm{A}$, B, C, D, etc., and further divided, such as platycodin

\section{PlatycosideE}
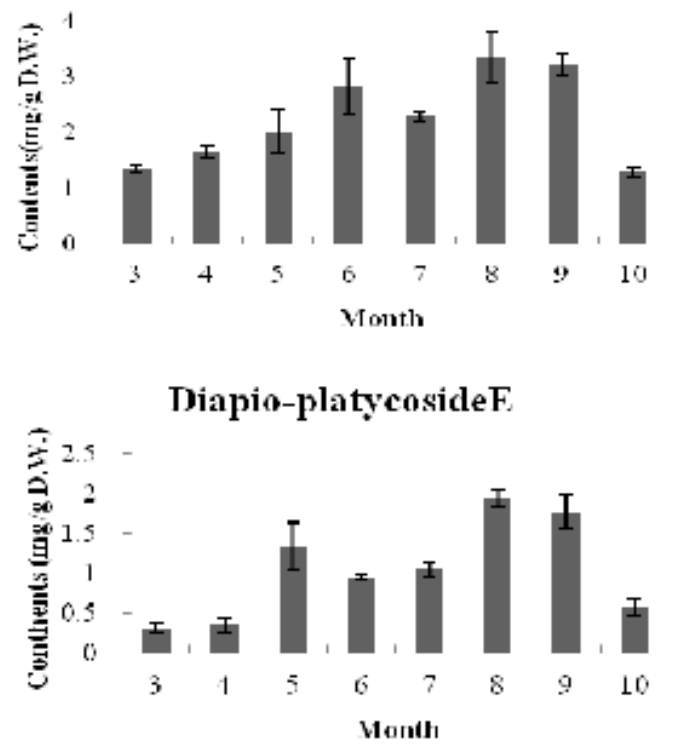

Platycodin 103

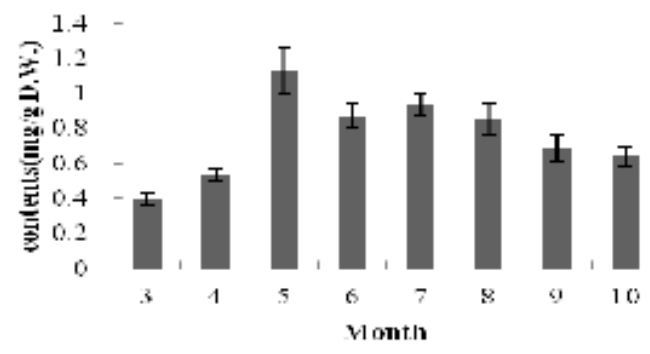

Platyconic acid

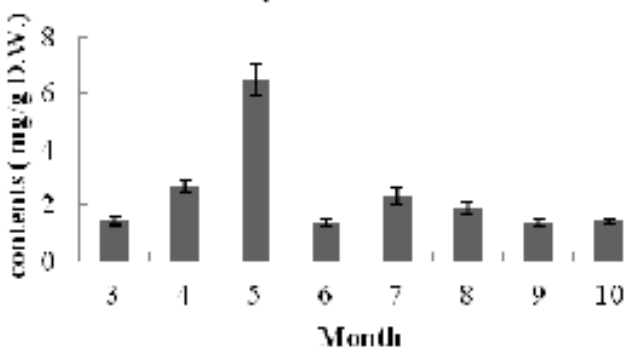

Fig. 1. Seasonal variation of saponin content in the root of balloon flower
$\mathrm{D}_{1}, \mathrm{D}_{2}, \mathrm{D}_{3}$, etc ${ }^{14}$. To the best of our knowledge, information regarding the saponin content in Platycodi Radix at different stages of root growth has not been published yet. Here in this study we reported the variation of saponin content at different growing times. In Korea, the chemical analysis of platycodon active constituents was initiated in 1930's and further elaborated in Japan during 1970's. The reports claimed that the root contains a large group of oleanane-type (triterpene) saponins. In the Pharmacopoeia of China (1988) stated that the commonly marketing and cultivating Platycodi Radix verities should contain not less than $6 \%$ saponins. However, the present study, platycodon saponin content from several samples showed that the wild roots of platycodon contained $7.3-11.8 \%$ saponins; cultivated roots had $1.7-14 \%$ saponins $^{15}$. Whereas the level of crude saponins in platycodon was said to be $2 \%$ in a medicinal grade material in Korea reported by Kim et al., 1995 etc $^{16}$. In Korea, it is noted that the content of saponins varies with respect to the climatic condition than in China. Similarly, in a report from Japan claimed that the individual and total content were different with related to the cultivation conditions ${ }^{17}$. The content of 4 major saponins varied largely among different growing times indicates that climatic and edaphic factors are directly involved for saponin content. The variation of saponin content varied with reagions, environmental conditions were reported by several investigation ${ }^{15-18}$. Those findings are directly coincided with our findings. In another study, Lobstein et al. reported that the content of flavonoids and other phenolic compounds varied among seasons in crude leaf extracts of Ginkgo biloba. Greater amounts of acylflavonol glycosides were found in buds, while flavonol glycosides were found in spring leaves and biflavones were observed in autumn leaves ${ }^{19}$. Similarly, Kang and Kang et al. found seasonal variation of flavonoid glycosides in Epimedium koreanum, and Yoo et al. found variability in the berberine content of Berberis koreana ${ }^{20,21}$.

\section{CONCLUSION}

In conclusion, as part of our studies, we have described the variability of different saponin contents in the root of balloon flower, according 
to season and different lengths of the growing period. The information presented here provides a useful reference for determining appropriate harvest times of Platycodi Radix to maximize saponin extraction.

\section{ACKNOWLEDGEMENTS}

This study was supported by the Regional Innovation Center For Dental Science \& Engineering, Chosun University, Gwangju, Korea (B0008940).

\section{REFERENCES}

1. Ishii, H., Tori, K., Yoshimura, Y. Saponins from the roots of Platycodon grandiflorum. Part 1. Structure of prosapogenins. J. Chem. Soc. Perkin Trans., 1981;1: 1928-1933.

2. Ishii, H., Tori, K., Tozyo, T., Yoshimura, Y. Saponins from roots of Platycodon grandiflorum. Part 2. Isolation and structure of new triterpene glycosides. J. Chem. Soc. Perkin Trans., 1984;1: 661-668.

3. Kubo, M., Nagao, T., Matsuda, H., Namba, K. Immune pharmacological studies on platycodi radix I: Effect on the phagocytosis in mouse. Shoyakugaku Zasshi, 1986;40: 367-374

4. WHO (World Health Organization). WHO Monographs on Selected Medicinal Plants, Geneva, 1999:213.

5. Kim, H.K., Kim, D.S., Cho, H.Y. Protective effects of Platycodi radix on alcohol-induced fatty liver. Biosci. Biotechnol. Biochem., 2007;71:1550-2.

6. Kim, Y.P., Lee, E.B., Kim, S.Y., Li, D., Ban, H.S., Lim, S.S., Shin, K.H., Ohuchi, K. Inhibition of prostaglandin $\mathrm{E}_{2}$ production by platycodin D isolated from the root of Platycodon grandiflorum, Planta Med., 2001;67: 362-364.

7. Cho, K.H., Park, J., Han, J., Jeong, T.S. Ligand binding domain of farnesoid $\mathrm{X}$ receptor revealed the best sensitivity and activity among FXR variants from fluorescence-based assay. Lipids, 2003;38:1149-1156.

8. Cho, K.H., An, S., Lee, W.S., Park, Y.K., Kim, Y.K., Jeong, T.S. Mass-production of human ACAT-1 and ACAT-2 to screen isoform-specific inhibitor: a different substrate specificity and inhibitory regulation. Biochem. Biophys. Res. Commun., 2003;309:864-872.
9. Ahn, K.S., Noh, E.J., Zhao, H.L., Jung, S.H., Kang, S.S., Kim, Y.S. Inhibition of inducible nitric oxide synthase and cyclooxygenase II by Platycodon grandiflorum saponins via suppression of nuclear factor-kB activation in RAW 264.7 cells. Life Sci., 2005;76: 2315-2328.

10. Han, L.K., Xu, B.J., Kimura, Y., Zheng, Y., Okuda, H. Platycodi Radix affects lipid metabolism in mice with high fat diet-induced obesity. J. Nutr., 2000;130:2760-2764.

11. Han, L.K., Zheng, Y.N., Xu, B.J., Okuda, H., Kimura, Y. Saponins from Platycodi Radix ameliorate high fat diet-induced obesity in mice. J. Nutr., 2002;132:2241-2245.

12. Yan, Y.Z., Xue, J.C., Wu, J.R., Yoo, D.S., Lee, S.Y., Kim, Y.K., Uddin, M.R., Park, S.U. Vatiation of triterpenoid saponins content in Platycodon grandiflorum (Jacq.) A. D.C. Asian J. Chem.,2002; 24: 1268-1270.

13. Fu, W.W., Shimizu, N., Takeda, T., Dou, D., Chen, B., Pei, Y.H., Chen, Y.J. New a-ring lactone triterpenoid saponins from the roots of Platycodon grandiflorum. Chem. Pharm. Bull., 2006;54: 1285.

14. Hsu, H.Y., Chen, Y.P., Hong, M. The Chemical Constituents of Oriental Herbs, Oriental Healing Arts Institute, Long Beach, CA. 1982.

15. Long, Q.Q. Total saponin contents of the root of wild and cultivated Platycodon grandiflorum. J.Chinese Med. Mater., 1989;12: 37-38.

16. Kim, K.S., Ezaki, O., Ikemoto, S., Itakura, H. Effects of Platycodon grandiflorum feeding on serum and liver lipid concentrations in rats with diet-induced hyperlipidemia. J. Nutr. Sci. Vitaminol., 1995;41:485-91.

17. Katsuko, H. Studies on the cultivation and preparation of platycodon root III. Chem. Pharmaceut. Bull., 1992;40: 1946-1947.

18. Pharmacopoeia Commission of PRC, Pharmacopoeia of the People's Republic of China (1988 English Edition), People’s Medical Publishing House, Beijing.

19. Lobstein, A., Rietsch-Jako, L., Haag-Berrurier, M., Anton, R. Seasonal Variations of the Flavonoid Content from Ginkgo biloba Leaves. Planta Med., 1991;57: 430-3.

20. Kang, S.S., Kim, J.S. Seasonal variation of flvonoid glycosides in Epimedium koreanum. $J$. Pharmacogon., 1991;22: 85-90.

21. Yoo, S.J., Lee, K.B., Kwak, J.H. Studies on the seasonal variation of berberine contents in Berberis koreana. Kor. J. Pharmacogon., 1986;17: 123-128. 